\title{
Design of Solar Powered Charging Backpack
}

\author{
Jonas Taverne ${ }^{1}$, Firdaus Muhammad-Sukki ${ }^{2}$, Ahmad Syahir Ayub ${ }^{3}$, Nazmi Sellami ${ }^{4}$, \\ Siti Hawa Abu-Bakar ${ }^{5}$, Nurul Aini Bani ${ }^{6}$, Abdullahi Abubakar Mas'ud ${ }^{7}$, Draco Iyi ${ }^{8}$ \\ ${ }^{1,2,4,8}$ School of Engineering, Robert Gordon University, Scotland, United Kingdom \\ ${ }^{3}$ Department of Electronic \& Electrical Engineering, University of Strathclyde, Glasgow, United Kingdom \\ ${ }^{5}$ Universiti Kuala Lumpur British Malaysian Institute, Selangor, Malaysia \\ ${ }^{6}$ UTM Razak School of Engineering and Advanced Technology, UniversitiTeknologi Malaysia, Kuala Lumpur, Malaysia \\ ${ }^{7}$ Department of Electrical and Electronic Engineering Technology, Jubail Industrial College, Saudi Arabia
}

\begin{tabular}{l}
\hline \hline Article Info \\
\hline Article history: \\
Received Sep 17, 2016 \\
Revised Nov 22, 2015 \\
Accepted Dec 3, 2016 \\
\hline Keyword: \\
Backpack \\
Charging circuit \\
Efficiency \\
Regulator \\
Solar cell
\end{tabular}

\begin{abstract}
This paper demonstrated a step by step process in designing a solar powered charging backpack that is capable of charging a mobile phone efficiently. A selection of existing products available on the market were reviewed and compared to ascertain the cost, size, and output capabilities. Next, the solar cell types and regulators were compared and their respective merits were also investigated. The charging system was then designed and tested before being integrated with the backpack. The results clearly showed that the system managed to charge the mobile phone. However, it was found that the excessive power dissipation has caused the linear regulator to generate significant heat.
\end{abstract}

Copyright $@ 2018$ Institute of Advanced Engineering and Science. All rights reserved.

\section{Corresponding Author:}

Firdaus Muhammad-Sukki,

School of Engineering, Sir Iain Wood Building,

Robert Gordon University,

Garthdee Road, Aberdeen, AB10 7GJ Scotland, United Kingdom

Email: f.b.muhammad-sukki@rgu.ac.uk

\section{INTRODUCTION}

Solar is one of the most abundant sources of renewable energy [1-4], with the potential capability of generating enough power to meet the demands of the entire planet. It was calculated theoretically that the amount of sun received on earth for one day has the capability to meet the demand of the world for more than 20 years [5]. Despite the huge potential, solar photovoltaic only provides $1.2 \%$ of the world's electricity [6]. The harnessing of solar energy is still very much ongoing with the advancements in solar technology constantly improving. There are many applications where solar energy is utilized - from the very big application, such as generating electricity for homes and industry from solar fields, to the very small applications like powering the calculators. The possibilities are extensive.

One of the products that utilises the solar energy is solar powered backpack. In terms of research, Malla et al. [7] analysed a solar powered backpack through buck boost converter to regulate the output voltage. They carried out various simulations in MATLAB to investigate the performance of their design, which showed good agreement when validated via experiments. Sulaiman et al. [8] investigated a solar-based wireless charging system and found that the mobile phone charged from this setup has superior standby time as compared to the wired charging system. Nahm [9] designed a solar backpack that comprised of 12 solar cell which was capable of charging a Blackberry Bold model 9780 by producing a minimum voltage of $4.2 \mathrm{~V}$ and minimum current of $0.25 \mathrm{~A}$.

There are a varying number of products already on the market that utilise solar energy for storing and charging devises. The products range in all shapes and sizes from fully integrated to attachable. As with 
the product, there is also wide range in prices from the $£ 30$ mark to well over $£ 200$. A selection of the products is presented in Table 1 . It should be noted that the prices obtained (22/02/2017) can be subject to change. It can be seen that all products use monocrystalline solar cell which had a stated conversion rate of $22 \%$. Generally, the power of the solar backpacks was ranging from $6 \mathrm{~W}$ to $7 \mathrm{~W}$ with the output voltage of between $5 \mathrm{~V}$ and $6 \mathrm{~V}$. The backpacks that come at greater cost tended to have a battery pack incorporated. The addition of this does increase the overall weight as expected.

The purpose of the paper is to develop a different prototype of solar powered charging backpack that is capable of charging a mobile phone efficiently. The design would have to meet certain criteria including durability, reliability, practicality and low cost. In order for this to be achieved successfully, research, design, testing and analysis are carried out.

Table 1. Selection of solar backpack in the market.

\begin{tabular}{ccccccc}
\hline Sold By & Watts & Voltage & Battery Bank & $\begin{array}{c}\text { Bag Size } \\
(\mathbf{L} * \mathbf{W} * \mathbf{H}) \\
(\mathrm{cm})\end{array}$ & $\begin{array}{c}\text { Weight } \\
(\mathrm{kg})\end{array}$ & Price \\
& $(\mathrm{W})$ & $(\mathrm{V})$ & & $(\mathfrak{)})$ \\
\hline Vitechbiz [10] & 6.5 & 6.0 & No & $35^{*} 22 * 52$ & 1.30 & 90.00 \\
TVCMALL [11] & 6.5 & 6.0 & No & $55^{*} 36 * 23$ & 1.35 & 40.40 \\
ECEEN [12] & 7.0 & -- & Yes (10AH) & $65 * 60 * 30$ & 2.00 & 139.99 \\
Sunsky [13] & 6.5 & 6.0 & Yes & $22 * 8.5 * 32$ & 1.80 & 71.99 \\
Glorysolar [14] & 7.0 & 5.0 & No & $55 * 36 * 23$ & 1.34 & 57.39 \\
\hline
\end{tabular}

The design of the charging circuit and the solar cell will need to meet the requirements of the mobile phone. The phone that will be used as a test is Vodafone's Smart First 7. The battery is Li-ion with a capacity of $1400 \mathrm{mAh}$, a nominal voltage of $3.7 \mathrm{~V}$ and a charge up voltage of $4.2 \mathrm{~V}$. The phone operates a micro USB charger connection on the phone side and a USB version 2.0 connection to charger [15]. The charging circuit should have the appropriate compatible USB connection.

\section{CHARGING CIRCUIT}

Within a charging circuit it is necessary to have a regulated voltage output to supply the charging capabilities to the load. Therefore, it is important to look at the different types of voltage regulators available. The two main types are switching and linear. Switching regulators can be broken down into buck types (stepdown), boost (step-up) and inverter types.

The main stipulation for the charging circuit is to regulate an output voltage of $5 \mathrm{~V}$ to satisfy the charging requirement for the phone battery. When comparing the linear with the switching regulator it is important to establish the most practical circuit with relation to efficiency and cost. The switching circuits have higher complexity when it comes to the external components. In comparison, the linear circuits' external components are reduced due to the linear operation of the regulator. The reduction in complexity relates to a cheaper circuit cost. However, the switching types have higher efficiencies which are at the expense of circuit complexity. The switching types are also capable of boosting as well as operating in buck mode. Despite this, switching regulators have a higher output voltage ripple owing to their switching nature, produce electromagnetic interference (EMI) and noise and are generally more expensive than linear regulators [16].

The main advantage of the buck and boost converters is the efficiency rates which can be greater than $90 \%$ [16]. This is due in part to the inductor which provides current to the load during off periods of the MOSFET instead of dissipating its stored energy as heat. This is also the case for the capacitor which charges during on periods and then supplies the load during the off periods and once the inductor has discharged. Some of the main advantages of the linear type are a lower output voltage ripple, transient response to any changes with the load, and low EMI and noise. The low noise and low EMI is attributed to the non-switching characteristics of the circuit and no inductors in operation. Linear regulators (LRs) have some disadvantages relating to their low efficiency, heat sink is required, unable to step down voltage.

Taking the advantage and disadvantages into consideration, the LR will be used as the voltage regulator. This is due to the lower cost associated with the external circuitry and regulator itself, EMI and noise reduction, and low output voltage ripple [17]. Consideration into operating with a low dropout regulator (LDO) was taken and despite being more efficient than LR, it was not deemed feasible. This was based on the fact that the LDO operates with low voltage drops (typically in $\mathrm{mV}$ ) [16]. This would become problematic when the weather conditions are such that the solar panel supply increases/decreases by one or more volts. 
The circuit comprises of a voltage divider to regulate the output voltage. A diode was used to protect the solar cell from reverse charge of the battery. The circuit, once designed will undergo tests and improvements made if necessary.

The first and most important component is the LR. Following the specifications of the mobile phone battery it is necessary to have an output of $5 \mathrm{~V}$ from the circuit as previously discussed. The input voltage will need to be of sufficient magnitude to allow for the regulated output voltage with relation to the minimum dropout voltage of the chosen regulator.

Several LR were looked at with relation to the adjustable output voltage range and the maximum output current. TS317CM was found to be suitable. The output voltage was adjustable over a range of $1.25 \mathrm{~V}$ to $37 \mathrm{~V}$ and a maximum output current of $1.5 \mathrm{~A}$ for package type TO-220. The regulator has several key internal protection feature such as thermal overload, short circuit current limiting constant with temperature and output transistor safe area compensation [16]. With these internal protection features it meant that external protection circuitry was reduced.

As stated, the regulated output voltage is set by a voltage divider connected to the adjust pin of TS317CM. $R_{2}$ can be a fixed resistor or a variable resistor to allow for variations of $V_{\text {out }}$. LTspice was used as the simulation software package to verify the output voltage. This was achieved by setting the resistance values in accordance to the calculated values and running the simulation. The simulated circuit and corresponding results can be found in Figures 1 and 2.

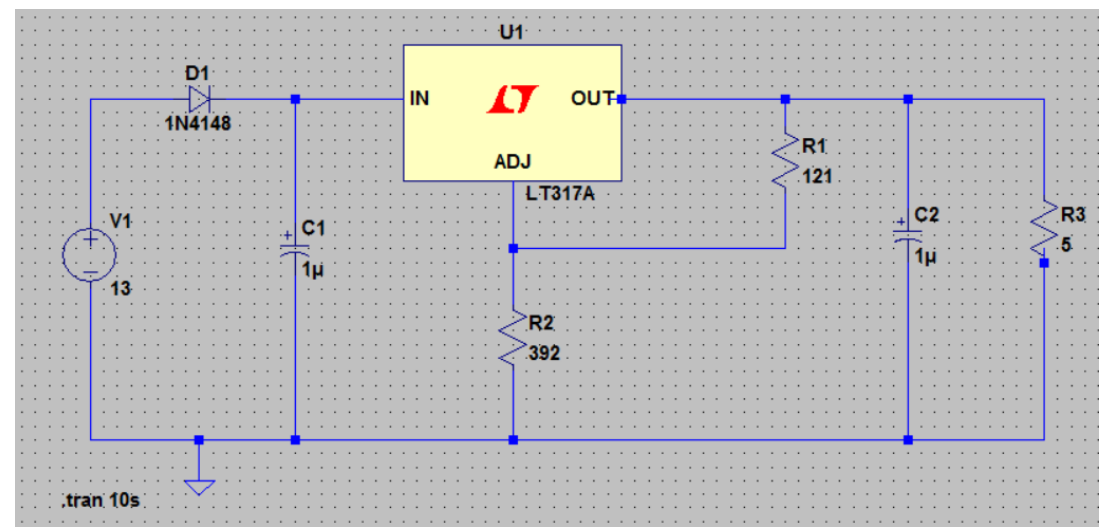

Figure 1. Simulated circuit design

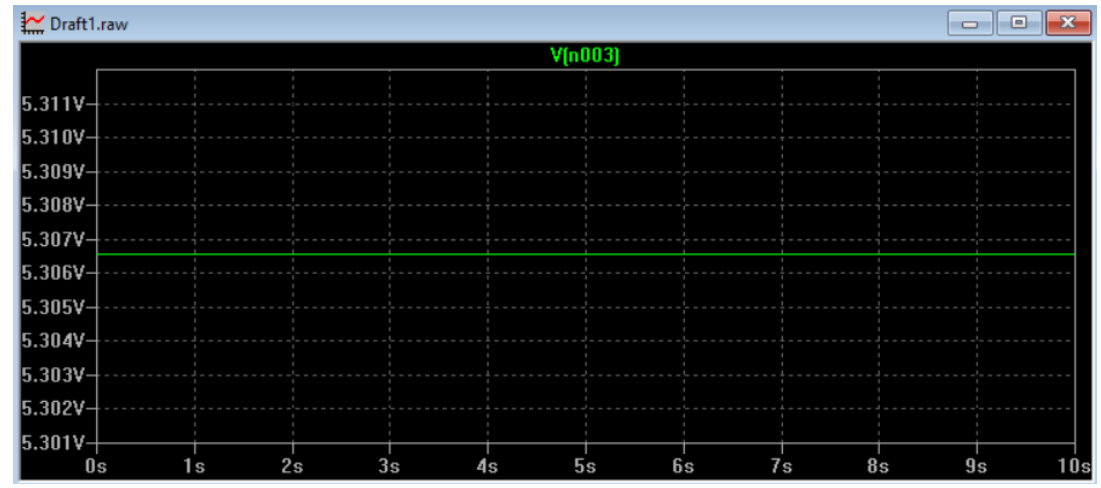

Figure 2. Simulated output voltage.

For simulation, a resistor was used as a load. Diode $D_{1}$ protects against reverse charge from the battery. The diodes rating needs to have a breakdown voltage that will maintain the correct biasing throughout circuit operation. The diode chosen for the constructed circuit was 1N4004 as this was more than capable so satisfying the operational criteria [17].

The value of $V_{\text {out }}$ was found from both calculation and simulation results. The equation used to find $V_{\text {out }}$ as stated in the datasheet was the following [16]: 


$$
V_{\text {out }}=V_{\text {ref }}\left(1+\frac{R_{2}}{R_{1}}\right)+I_{\text {adj }} R_{2}
$$

where $V_{\text {ref }}=1.25 \mathrm{~V}, I_{a d j}=100 \mu \mathrm{A}(\max )$ with typical value $=50 \mu \mathrm{A}[16]$, and $R_{1} \& R_{2}=121 \Omega \& 390 \Omega$ respectfully. The resistor ratio $\frac{R_{2}}{R_{1}}$ was found from simplifying Equation 1 by neglecting the addition of $I_{a d j} R_{2}$ giving:

$$
V_{\text {out }}=V_{\text {ref }}\left(1+\frac{R_{2}}{R_{1}}\right)
$$

Equation 2 can then be rearranged to find $\frac{R_{2}}{R_{1}}$ as shown in Equation 3.

$$
\frac{R_{2}}{R_{1}}=\left(\frac{V_{\text {out }}}{V_{\text {ref }}}\right)-1
$$

For an output voltage of $5 \mathrm{~V}$ gives a ratio of 3 , as shown:

$$
\frac{R_{2}}{R_{1}}=\left(\frac{5}{1.25}\right)-1=3
$$

The output voltage was then calculated using Equation 2 with all the parameters stated. The calculated result of $V_{\text {out }}=5.32 \mathrm{~V}$ which was just over the required operating voltage of $5 \mathrm{~V}$ was acceptable. Through simulation $V_{\text {out }}$ was shown to be $5.31 \mathrm{~V}$ as seen in Figure 2. It is clear to see form the specification that the results backup the calculated result.

An input capacitor will need to be used if the solar panel is connected an appreciable distance from circuit, as specified by the datasheet. The advantage of connecting a capacitor across the input $\left(C_{1}\right)$ will reduce the sensitivity to input line impedance [16]. Capacitor $C_{2}$ improves the transient response of the circuit which is specified in the datasheet along with the value of capacitance [16]. The voltage tolerance of the capacitors is such that the voltage values are greater than the circuit voltages as to maintain full capacitance operation value.

\section{SELECTION OF SOLAR CELL}

Selecting the appropriate solar cell/panel depends mainly on efficiency and cost. Tables 2 provides some of the advantages and disadvantage of the three different solar cell types. It can be seen from Table 2 that, in terms of efficiency, monocrystalline is the most efficient with polycrystalline and amorphous cell following second and third respectfully. One of the main reasons for the amorphous type having a significantly lower efficiency is because, when compared to monocrystalline, it is still a fairly new technology [18]. However, it is still necessary as comparison to the more established types.

Table 2. Advantages and disadvantages of solar cells

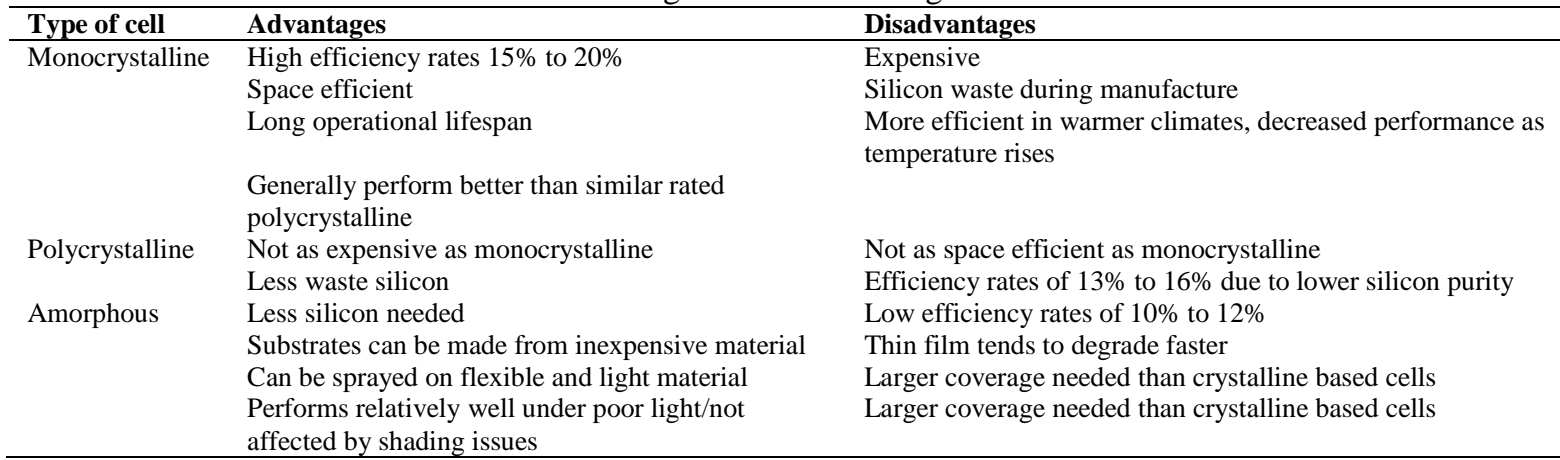

Monocrystalline has a lot of strong attributes, not only in high efficiency rates but also with its efficiency relating to space. With monocrystalline, the high rates of efficiency mean that the overall size of the cell/panel can be reduced. The general life-span of monocrystalline is greater than the other three types, 
given that manufacturers and sellers alike attaching a 25-year warranty [18]. The higher efficiency and longer life-span is represented in the cost, with monocrystalline being the more expensive.

Polycrystalline and amorphous types lack the higher efficiency rates of the monocrystalline. The space efficiency in the polycrystalline is less than that of the monocrystalline but does consume less silicon during manufacturing. The amorphous type, again, requires less material which is cheaper. The construction of amorphous solar cells makes them more flexible and lightweight. The operation of amorphous is such that it behaves 'good' under poor light and operates effectively in colder conditions [18].

The backpack that is to be used has an allowable amount of space which needs to come into consideration when the choice is made. This will also have an impact as the limited space will mean an efficient solar type will need to be selected. It is therefore determined that monocrystalline will be used. Despite the higher costs incurred, the reasons stated above outweigh the higher costs.

The rating of the solar cell/panel is determined by the type of voltage regulator (switching or linear) used in the charging circuit. As the selected regulator is of the linear type, there needs to be compensation for the minimum allowable voltage drop as stated by the regulator. Therefore, the rating of the solar panel needs to take this factor into consideration. The LR has an allowable minimum volt drop of $2 \mathrm{~V}$ which when added with the USB voltage of $5 \mathrm{~V}$ relates to a minimum panel rating of $7 \mathrm{~V}$. After some consideration, two $6 \mathrm{~V} 6 \mathrm{~W}$ rated monocrystalline solar cells connected in series are used to supply more than $7 \mathrm{~V}$ to the charging circuit.

\section{TESTING}

Initial testing of the circuit was carried out using the designed circuit to charge the mobile phone. The initial battery percentage was recorded and checked every 5 minutes over an appreciable period. The input and output voltages as well as the current to the load were recorded. The test was carried out under both cloudy and clear days to achieve a clear comparison of the operation of the circuit. During both test conditions the cells were placed as close to $90^{\circ}$ to the sun as possible with no obstructions.

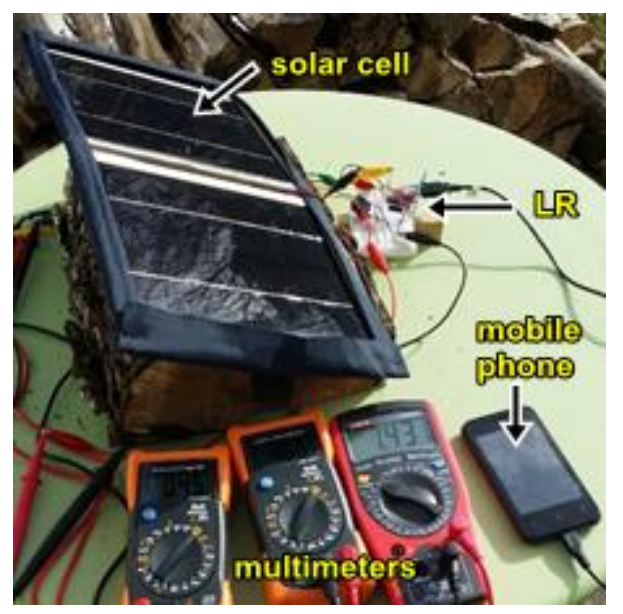

Figure 3. Testing setup

Figure 3 shows the test setup. The testing was carried out in a number of days. The following is the test carried out was under cloudy weather conditions on date 06/04/017 in Aberdeen, Scotland. The panel is assume to be static, and was place in an open space with no shading from nearby buildings. The start charge of the battery was $2 \%$. Figure 4 shows the increasing charge of the battery over the test time. As previous, there is little increase within the first twenty minutes of charge. Within the next forty minutes of charge there is a significant increase in the batteries capacity. From time, 16:05 onwards, the increase becomes more gradual as the battery capacity increases. 


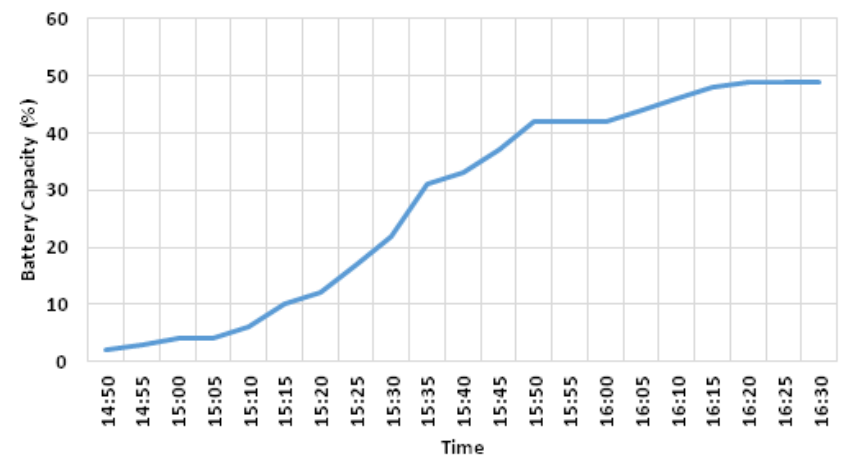

Figure 4. Battery capacity test

As can be seen from Figure 5, the current did not deviate from its max output of $450 \mathrm{~mA}$ throughout the test. This was due to the input voltage maintaining above the allowable volt drop of the circuit, as observed from Figure 6.

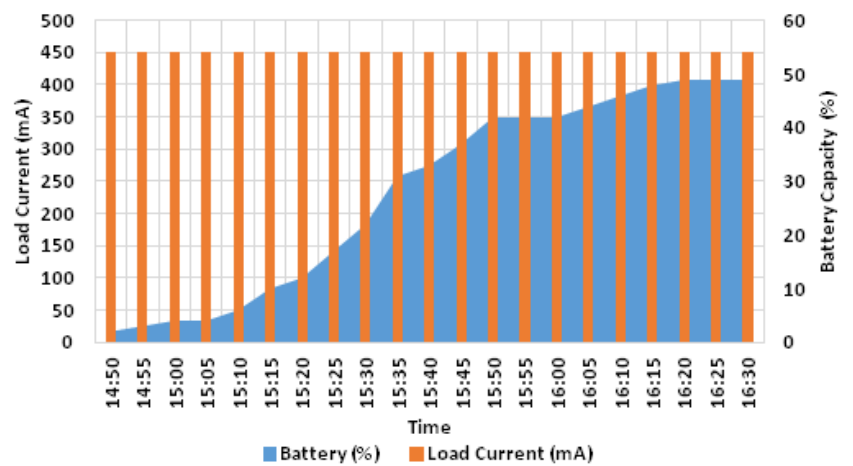

Figure 5. Load current test

The efficiency can be calculated from the following Equation (5) [16]:

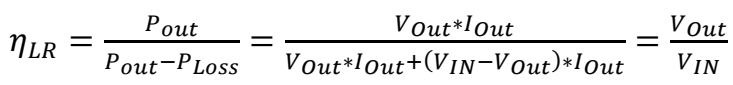

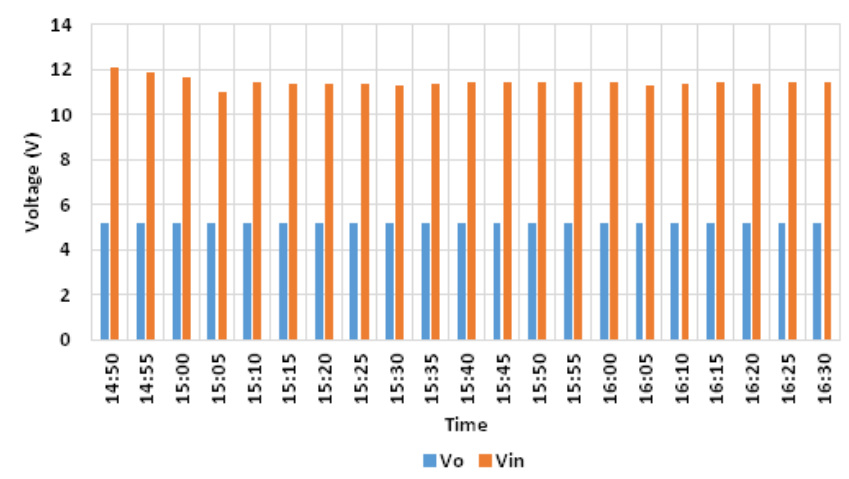

Figure 6. Input and output voltage comparison test 


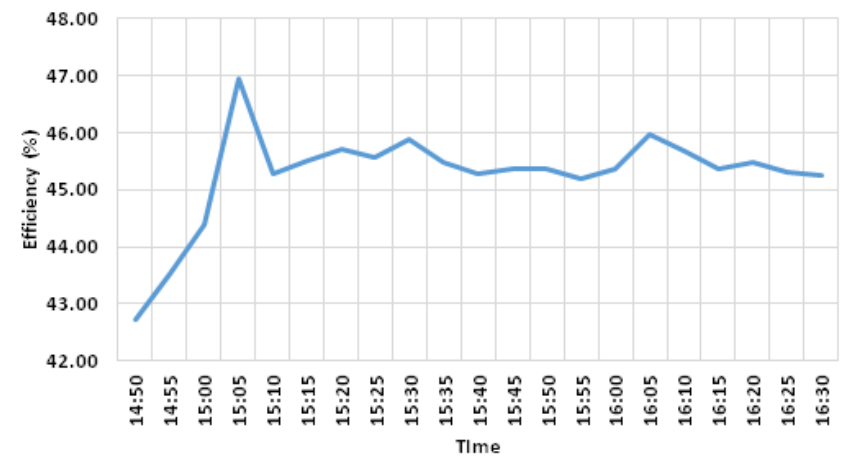

Figure 7. Efficiency test

From Figure 7, it clearly shows the efficiency of the circuit to be around the $45.5 \%$ mark. The lowest efficiency was recorded a $42.73 \%$ and the highest at $46.96 \%$. The result of which meant a large amount of power was dissipated as heat causing TS317CM to heat up significantly. The tests have shown that the circuit was successful in charging the phone. It is also clear to see the importance of matching the correct rating of cell to the characteristics of the circuit. The two cells test showed that the higher input voltages would result in lower efficiencies and cause excessive heating of the LR. In the future, it is suggested that a single cell is used to provide both the higher efficiencies and appropriate input voltage levels to maintain correct operation of the charging circuit.

\section{INTEGRATION OF COMPONENTS}

The most important consideration during integration is to maintain the integrity of the solar panel and charging circuit. The system needs to be robust but still operate effectively. The two main options for integration is either fully integrated or partially.

Requirements for full integration:

a. Water-resistant

b. Shock resistance

c. Aesthetically acceptable

Requirements for partial integration:

a. Easily attachable

b. Small package footprint for storage

c. Robust

d. Aesthetically acceptable

e. Water-resistant

There are several advantages and disadvantages to both systems. The benefit with a fully integrated system is that it comes as a complete package with no need to attach the panel. In contrast the partial method allows for the product to be removed completely if not in use. The product can then be stored safely without the possibility of getting damaged. Each cell used has the following dimensions: $165 \mathrm{~mm}$ x $165 \mathrm{~mm}$. As stated above the system would have to adhere certain requirements.

The design that was looked at was using the 2 cells as shown in Figure 8 . The design was meant to be such that the panels could be attached and removed when necessary. For this arrangement, a book like design was constructed. There were no costs during the design/construction of the integration process as all materials were recycled/re-purposed materials. 


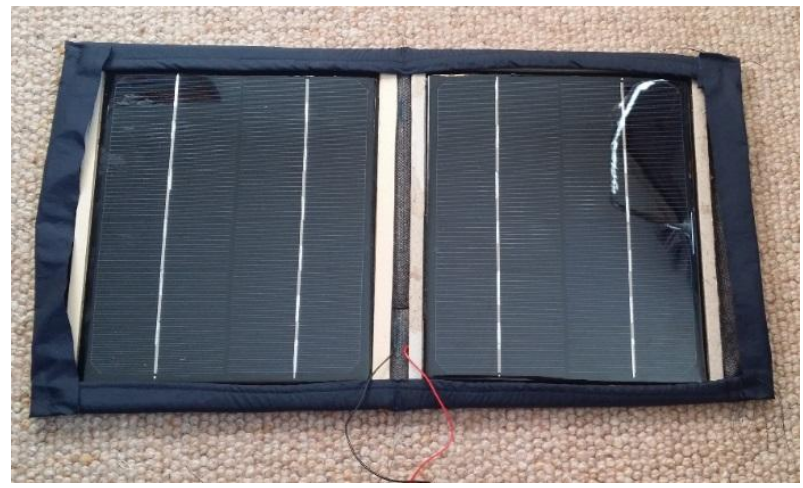

Figure 8. Two-cell series connection integration design

The design could then be attached using Velcro straps. The panels are protected by a cardboard backing and edging to provide some shock absorption. The cardboard frame is enclosed in a denim material which will allow a degree of ware-and-tear. The whole panel design, when removed, can be folded and stored away protecting the panels. This design does have some disadvantages when it comes to overall size which does impact the aesthetics. However, there is the added advantage that this design can be removed and placed in the optimum position when stationary. An example of a final product of a solar powered charging backpack integration is presented in Figure 9.

It is also good to estimates the cost to produced this prototype. Table 3 shows the breakdown cost of the components to produce the backpack. Other costs such as delivery cost, labour cost etc. are excluded from the calculation. The cost to produce the prototype was approximately $£ 38.38$. If we consider to mass produce this product, its production cost can be further reduced and could potentially compete with the existing products available in the market.

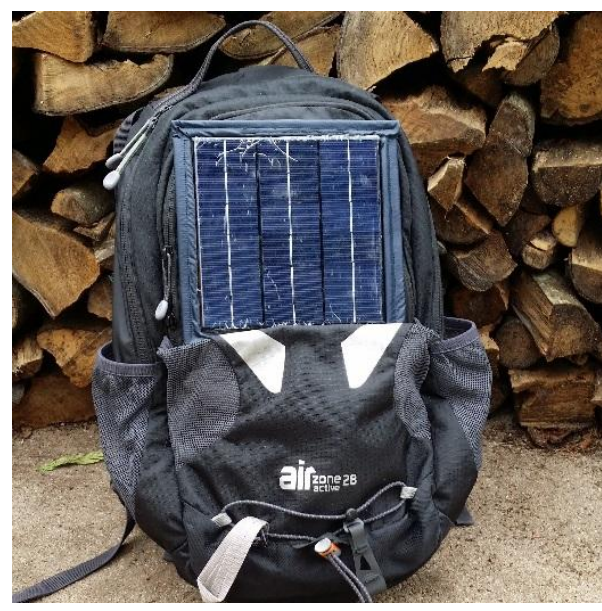

Figure 9. Final product - using one cell integration

Table 3. Breakdown cost to produce the prototype (in $£$ ).

\begin{tabular}{crcr}
\hline Components & Cost & Quantity & Total \\
\hline Solar Panel & 12.49 & 1 & 12.49 \\
TS317CM & 0.59 & 1 & 0.59 \\
Heat Sink & 1.29 & 1 & 1.29 \\
USB type A & 3.42 & 1 & 3.42 \\
Backpack & 10.00 & 1 & 10.00 \\
Circuit Box & 5.49 & 1 & 5.49 \\
Sundries* & 5.00 & - & 5.00 \\
TOTAL & & & 38.28 \\
\hline
\end{tabular}

*This includes solder, wire and small cost components like resistors, diode and capacitors.

\section{CONCLUSION}


There have been advances in solar technology with relation to the different solar cell; however monocrystalline still holds the higher efficiency rates which made it the logical choice when selecting the appropriate type. This was reflected in the research and tests carried out. It must be concluded that despite the higher efficiency ratings of monocrystalline, amorphous solar cells have the ideal physical properties with relation to flexibility. With greater efficiencies in amorphous cells would result in a more adaptable product.

The overall design and operation of the circuit managed to successfully charge the mobile phone with acceptable efficiency ratings. The circuitry was kept simple but effective as a result of utilising the LR. This meant that the cost was kept to a minimum.

The tests carried out under varying weather conditions clearly showed that the system managed to charge the mobile phone. However, it was found that the excessive power dissipation has caused the LR to generate significant heat. In the future, it is suggested that a single cell is used to provide both the higher efficiencies and appropriate input voltage levels to maintain correct operation of the charging circuit.

The integration of the system with the backpack was vital as the aesthetics of the final product was important to uphold. The choice of making the product a partial integration was due to versatility. The system could be removed and integrated with other backpacks easily making it a more attractable solution.

\section{ACKNOWLEDGEMENTS}

The author would like to thank Ministry of Higher Education (MOHE), Malaysia and Universiti Teknologi Malaysia (UTM) (Research cost centre no. Q.K130000.2540.16H95) for funding part of this project.

\section{REFERENCES}

[1] Verayiah R, Iyadurai A. A comparison study on types of PV for grid connected photovoltaic power. Indones J Electr Eng Comput Sci 2017;6:349-56. doi:10.11591/ijeecs.v6.i2.pp349-356.

[2] Chahid EH, Oumhand MI, Malaoui A. A fast strategy to determine the physical and electrical parameters of photovoltaic silicon cell. Int J Appl Power Eng 2017;6:104-13. doi:10.11591/ijape.v6i2.pp104-113.

[3] Shneen SW. Advanced optimal for power-electronic systems for the grid integration of energy sources. Indones $\mathbf{J}$ Electr Eng Comput Sci 2016;1:543-55. doi:10.11591/ijeecs.v1.i3.pp543-555.

[4] Krautmann J, Zhu J. Photovoltaic solar energy systems: Market trends in the United States. Int J Appl Power Eng 2012;1:12-128.

[5] Chu Y. Review and Comparison of Different Solar Energy Technologies. California, USA: 2011.

[6] REN 21. Renewables 2017: Global Status Report. Paris, France: 2017. doi:10.1016/j.rser.2016.09.082.

[7] Malla SG, Deepu DJ, Kumar DP, Malla JMR. Solar powered mobile phone: An innovative experiment. 2016 Int. Conf. Signal Process. Commun. Power Embed. Syst., IEEE; 2016, p. 1015-20. doi:10.1109/SCOPES.2016.7955594.

[8] Sulaiman N, Jadin MS, Hadi AA, Najib MS, Ahmad MA, Yusuf NSA. Evaluation of Mobile Phone Wireless Charging System Using Solar and Inductive Coupling. In: Akagi M, Nguyen TT, Vu DT, Phung TN, Huynh VN, editors. Adv. Intell. Syst. Comput., Springer, Cham; 2017, p. 238-47. doi:10.1007/978-3-319-49073-1_26.

[9] Nahm A. The solar charging backpack. The Menlo Roundtable 2011;10:79-110.

[10] Vitech Internet Limited. Solar Backpack with 6.5W Mono Crystalline High Efficiency Solar Panel 2017. https://www.ebay.co.uk/itm/Solar-Backpack-with-6-5W-Mono-Crystalline-High-Efficiency-Solar-Panel/262838385200 (accessed January 10, 2018).

[11] TVCMALL. Polyester Solar Backpack Bag 6.5W 6V Solar Panel with 5V 1A Output 2017. https://www.tvcmall.com/details/polyester-solar-backpack-bag-6-5w-6v-solar-panel-with-5v-1a-output-sku85020004a.html (accessed January 10, 2018).

[12] ECEEN Ltd. Solar Powered External Frame Pack 2016. https://www.ebay.co.uk/itm/ECEEN-Solar-PoweredBackpack-External-Frame-Hiking-Bag-Pack-with-7-Watts-Solar-/263199382847 (accessed January 10, 2018).

[13] Sunsky. Portable and Fashionable Outdoor Solar Charger Backpack 2017. https://www.sunskyonline.com/view/434419.htm (accessed October 13, 2017).

[14] Glorysolar. Glorysolar® 7Watts Solar Backpack/Solar Panel Bag /Solar Panel Charger for Mobile Phones 2017. https://www.amazon.co.uk/Glorysolar-7Watts-Backpack-Charger-Mobile/dp/B01E16SY9W (accessed October 13, 2017).

[15] GSMArena. Vodafone Smart First 7 2016. https://www.gsmarena.com/vodafone_smart_first_7-8100.php (accessed January 10, 2018).

[16] Zhang HJ. Basic Concepts of Linear Regulator and Switching Mode Power Supplies. vol. 140. 2013.

[17] ON Semiconductor. 1N4001 - 1N4007: General-Purpose Rectifiers. 2014.

[18] Maehlum MA. Which Solar Panel Type is Best? Mono- vs. Polycrystalline vs. Thin Film. Energy Inf 2017. $\mathrm{http}: / /$ energyinformative.org/best-solar-panel-monocrystalline-polycrystalline-thin-film/ (accessed January 10, 2018).

\section{BIOGRAPHIES OF AUTHORS}




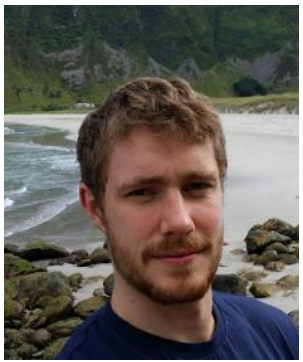

Jonas Taverne obtained his HND fin Electrical and Electronic Engineering from North East Scotland College in 2015. Subsequently, he pursued his BEng in the same are in Robert Gordon University and graduated in 2017. His research interest includes solar energy and renewable technology.

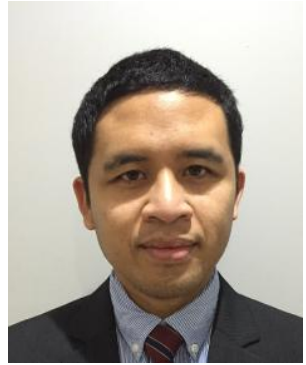

Firdaus Muhammad-Sukki received his MEng degree in Electrical and Electronic Engineering from Imperial College, London in 2006. In 2009, he pursued his postgraduate study in Glasgow Caledonian University from which he obtained his PhD in 2013. Dr. Muhammad Sukki is a Chartered Engineer, a member of the Institution of Engineering and Technology (IET) and an associate of the City and Guilds, London (ACGI). Dr. Muhammad Sukki is currently a Lecturer in Robert Gordon University, United Kingdom. His research interest lies in designing optical concentrator, which can be used in many applications including creating a low cost solar photovoltaic system, illumination, heating and cooling of buildings, energy harvesting, desalination, medical devices, waste water treatment etc. On top of that, Dr. Muhammad Sukki also carried out a number of non-technical research including market trend and financial analysis related to renewable technologies for countries such as Malaysia, Japan, Nigeria, Cameroon and United Kingdom. He has excellent track record in collaborating with research universities around the world. He has published numerous articles in high impact factor journals (e.g. Nature, Renewable \& Sustainable Energy Reviews, Applied Energy, Energy etc.), as well as presenting in various conferences related to his area. Prior to joining the academia, he was a communication engineer in Malaysia's largest telecommunication company.

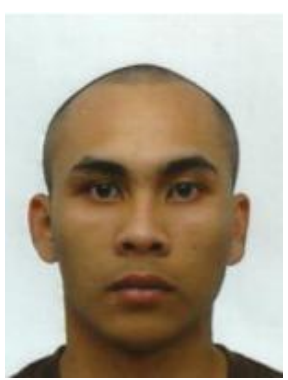

Ahmad Syahrir Ayub received B. Eng (Hons) in Electrical \& Electronic Engineering from Cardiff University, Wales, UK in 2007. In 2008, he was working in the area of cable diagnostics in the High Voltage Technologies (HVT) Group at University of Strathclyde, Glasgow, Scotland. Currently, he is pursuing his PhD in Lightning Protection of Wind Turbine Blades at University of Strathclyde, Glasgow, Scotland. His areas of interest include lightning protection and cable diagnostics. He is a Student Member of both IET and IEEE.
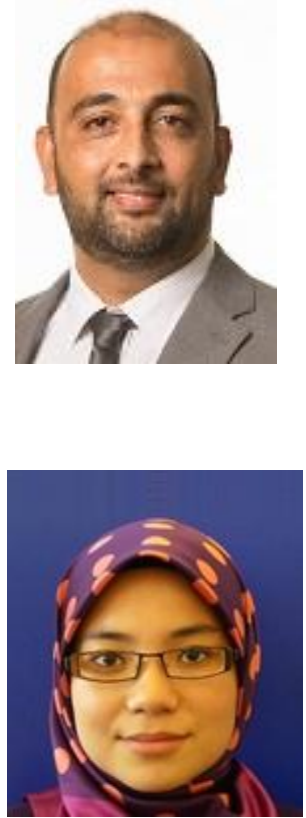

Nazmi Sellami received an MEng degree in Mechanics and Energetics from Ecole Polytechnique Universitaire de Marseille, France (2004). After a period of work in the industry at Oxford Instruments, he returned to University to obtain an MSc in Renewable Energy Engineering from Heriot-Watt University, Edinburgh with distinction (2009) and was offered a scholarship to commence a $\mathrm{PhD}$ at the same establishment. He completed his thesis on the design of novel solar concentrator for building integration in 2013. Before joining RGU as a lecturer in Mechanical Engineering, Dr Sellami worked as a research fellow at Exeter University and an Associate Professor in Mechanical Engineering at Heriot-Watt University, Dubai Campus. Dr Sellami has been awarded an "Outstanding Impact award in Sustainable Future" with a group of researchers at the University of Exeter. His research interests include the characterisation and design of thermal and photovoltaic solar devices for various types of applications, and especially for building integration.

Siti Hawa Abu-Bakar obtained her BEng in Information Systems Engineering from Imperial College, London in 2006 under the MARA scholarship. In 2007, she joined Prokhas Sdn. Bhd., a wholly-owned company under the Ministry of Finance Malaysia as the Executive Trainee. From 2008 onwards, she becomes a unit trust consultant for Public Mutual Bhd. In 2011, she was awarded studentships from GCU and Scotland's Energy Technology Partnership (ETP) to pursue her post graduate study in solar technology from which she obtained her PhD in 2016. Dr AbuBakar is an associate of the City and Guilds, London (ACGI). Her interests include solar PV, solar thermal, financial planning and investment analysis. 


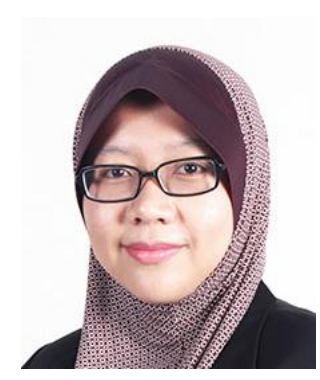

Nurul Aini Bani received her M.Eng degree in Electrical Engineering from University of Southampton, UK in 2006 where she received two academic awards for outstanding academic performance. She received her $\mathrm{PhD}$ degree in Electrical Engineering from Universiti Teknologi Malaysia, Malaysia in 2016. Her research interests include polymeric insulation material, space charge measurement, high voltage cable, renewable energy and rehabilitation engineering. She has authored and co-authored several papers in various technical journals and conference proceedings. She is now a lecturer in the Department of Engineering, UTM Razak School of Engineering and Advanced Technology (RSEAT).

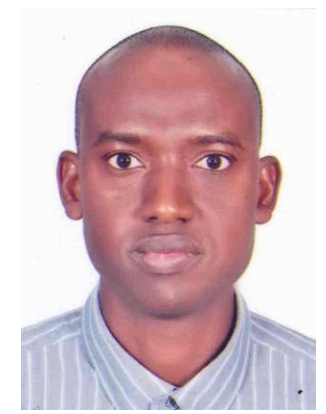

Abdullahi Abubakar Mas'ud received his BEng degree in Electrical Engineering in 1999 and Msc in Electronics and Communication in 2006, both from Ahmadu Bello University, Zaria, Nigeria. He also obtained a PhD in Electrical Engineering in 2013 from the Glasgow Caledonian University, Scotland, UK, under the supervision of Prof. Brian Stewart and Prof. Scott McMeekin. In 2002 he became an assistant lecturer in the Faculty of Engineering at the Ahmadu Bello University, Zaria, Nigeria. In 2013 he joined Jubail Industrial College, Saudi Arabia, and is currently an Assistant Professor in the Department of Electrical and Electronic Engineering. Dr. Abdullahi has published a number of papers in high impact factor journals and conference proceedings in the area of high voltage partial discharge and renewable energy. Dr. Abdullahi A Mas'ud is a Member of the IET, International association of Engineers and a registered Engineer (COREN) Nigeria.

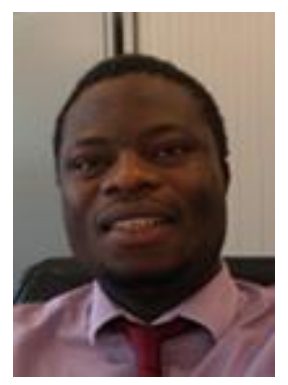

Draco Iyi obtained his MSc and PhD degrees in Mechanical Engineering at Northumbria University in 2009 and 2013 respectively. His doctoral research focused on buoyancy driven turbulent flows associated with radiation in a high density enclosure. Dr Draco joined Robert Gordon University in August 2014 as a full time member of the School of Engineering. Prior to this, he was a lecturer in the department of Mechanical and Construction Engineering at Northumbria University, Newcastle upon Tyne, where he was involved in research, teaching and learning activities at undergraduate and postgraduate level. Dr Draco has been involved in various consultancy activities with clients on developmental projects in thermos-fluid, CFD and process design engineering. Dr Draco also had several industrial work experiences and currently working on the design of experimental techniques to supply reliable data for the validation of CFD codes and techniques. 